\title{
Rhythms of Renewal of the City
}

\author{
Filipe Brandão \\ ISCTE-IUL / ISTAR-IUL, Portugal \\ fjsbo@iscte-iul.pt \\ Ricardo Correia \\ ISCTE-IUL / ISTAR-IUL, Portugal \\ rfmcj@iscte-iul.pt
}

\author{
Alexandra Paio \\ ISCTE-IUL and Vitruvius FABLAB/ISTAR-IUL \\ Portugal \\ Alexandra.paio@iscte.pt
}

\begin{abstract}
In the last few years, building renovation has gained an unprecedented relevance in Portugal, yet it is an asymmetric and urban phenomenon for the study of which, in space and in time, traditional statistic tools have limitations. Using computational tools, it is possible to generate maps that correlate building permits georeferenced data and their processing time. Using Lisbon City Hall database of planning applications and georeferenced vector information, two approaches are developed to represent the internal dynamic of renewal of the city between 2010 and 2016. These maps can be useful to improve the accessibility of planning information to citizens.
\end{abstract}

Keywords: Urban renewal; Building renovation; Lisbon; Time; Representation

\section{Introduction}

Building renovation in Portugal has increased comparatively to the construction of new buildings, in a context of decreasing activity of the building construction sector (INE, 2016). This urban renewal process seems to be concentrated on historic city centers, mainly of Porto and Lisbon, and their 1800's expansions. Since the 70's, the former have grown increasingly mono-functional, focused on commerce and services, and more recently have also been abandoned by these sectors which sought to relocate to other centers within the respective metropolitan areas or to other countries. It differs from traditional top-down urban renewal processes in that there has been no use of expropriation or large scale demolitions to give way to redevelopments. And although it isn't a bottom-up led process, since there has been a sustained public policy of promoting renovation of old buildings, such as by passing an exception regime for buildings older than 30 years or by reducing taxation on building permits for renovation, the dispersion of the property in small plots makes it very fragmented and interspersed, both in time and in space. Since it is an ongoing process which is happening within the cities, traditional national statistical tools, even at the city level, have severe limitations in correctly representing it.

Urban renewal can be represented and visualized with a different set of tools than the ones used until two or three decades ago and that concerns both visualization applications, datasets availability and geospatial data with time varying records. In 1976, Batty presented a seminal work on modelling urban growth and his work on city modeling goes through five decades with recent work on models with time-based data (Batty, 2015). Besides urban modelling, cities cartographic representation of time based data had a great development in last decade, with Carlo Ratti and MIT's Senseable City Lab. Since Real Time Rome (Ratti, 2006) they developed scientific work in this area with time based data but often specially based on mobile phone operator data or Radio-frequency identification (RFID) tags.

The use of computational tools allows the generation of maps, which can be updated in real-time, where geolocation data of buildings is merged with the duration of building permit approvals. Using Lisbon City Hall database of planning applications and the georeferenced vector information, two approaches are developed to represent the internal dynamic of renewal of the city between 2010 and 2016. Crossreferencing the application admission dates of building permits with the building permit issuing date and the GIS code, it is possible to know where in the city Renovation is happening and at what rate. This methodology is them applied to Toronto, using publicly available data of the location, application admission and issuing dates of building permits.

These maps could be useful to represent and understand dispersed urban phenomena, happening inside the city, thus providing information and insights on these processes that can be used to support public policy making and urban planning. These maps could also be useful to communicate complex geospatial data to lay citizens.

\section{Computation in Urban Planning}

The representation of the time variable on cartography can be traced back to Charles Joseph Minard, whom, in 1812, was able to map the army personnel and supplies flows for the Napoleon invasion of Russia (Robinson, 1967). With his data centric thematic cartography, Minard started to shape a new form of geospatial representation which with the evolution of information technologies, particularly in the last three decades, and the exponential growth of the availability of georeferenced data has generated new forms of representation of data which 
some authors name "urban big data"(Claudel, Nagel and Ratti, 2015) or "Big Data In and For Cities" (Batty, 2015).

The use of computers in urban planning and architecture started in the 1960s with architects with mathematical background, like Lionel March and Christopher Alexander, who could deal with the complex early computers (Bruton, 1997). In the essay "City is not a Tree", Alexander (1966) introduces the idea of complexity of the city: the natural city, with a semi lattice structure, versus the artificial or planned city with a tree like structure. This complexity poses a great challenge to the city representation with possible implications in planning. Authors like Batty or Steadman highlighted the more realistic representation of Alexander. While Steadman emphasized the biological analogy and the use of cybernetics to describe the city (Steadman, 1979), Batty accentuated the circumstance that Alexander's semi-lattice city representation could me more realistic (Batty, 2006). Like Alexander, Batty used the computer for city complexity problems, in his 1976 work, "Urban Modeling", he presents ways of modelling and representing population dynamics. With the development of Geographic Information Systems (GIS) in the nineties, Batty evolves his investigation towards the representation of the city with fractals (Batty and Longley, 1994) and cellular automata (Batty and Xie, 1994). Batty kept researching urban modelling, resorting in particular to cellular automata until today (Batty, 2012, 2016).

A different research thread on representing time data has been followed over the past decade by Carlo Ratti, the current MIT Senseable City Lab director. The best example of which is Real Time Rome (Ratti, 2006) project presented at the 2006 Venice Biennale. In this project, using time based data from several sources, but mainly from cell phones, a large database of synchronized data was created with the aim of characterizing urban behavior patterns and representing them through estimated people flows. Ratti and the Senseable City
Lab have also evolved to smaller scales such as in the Trash Track project (Offenhuber, Wolf and Ratti, 2013), where urban waste flows are analyzed with the use of Radio Frequency Identification (RFID) and GPS.

New forms of representation made accessible by ubiquitous computing and availability of datasets containing time-based information can help to understand and portray the urban renewal phenomenon. Unlike urban sprawl, an "unplanned, incremental urban growth which is often regarded unsustainable" (Batty, Besussi and Chin, 2003, p. 1), this process is an internal dynamic to the city which is not clearly visible or easy to represent. The present article presents an ongoing research that seeks to represent and characterize the renewal processes of cities.

\section{Methodology}

The data used in this work was requested to the Lisbon City Hall, to whom it belongs. It is composed of georeferenced vector information, in shapefile format, and a database with application admission, approval and issuing dates of building permits; administrative proceeding and building permit types; a building unique ID; building type amongst other types of administrative specific information. The building permit type is the key information that allows to discriminate permit applications for new building from renovation permits. Overall there are 12 categories that can be divided into 3 groups: Construction, Renovation and Others. The Renovation group contains 4 categories: Alteration, Expansion or Addition, Reconstruction and Conservation. The Construction group only contains new building permits and the Others group is comprised of administrative procedures without urbanistic relevance, that make changes to ongoing permits or that cannot be included in the previous groups. For this reason, the Others group wasn't included in the visualisation.

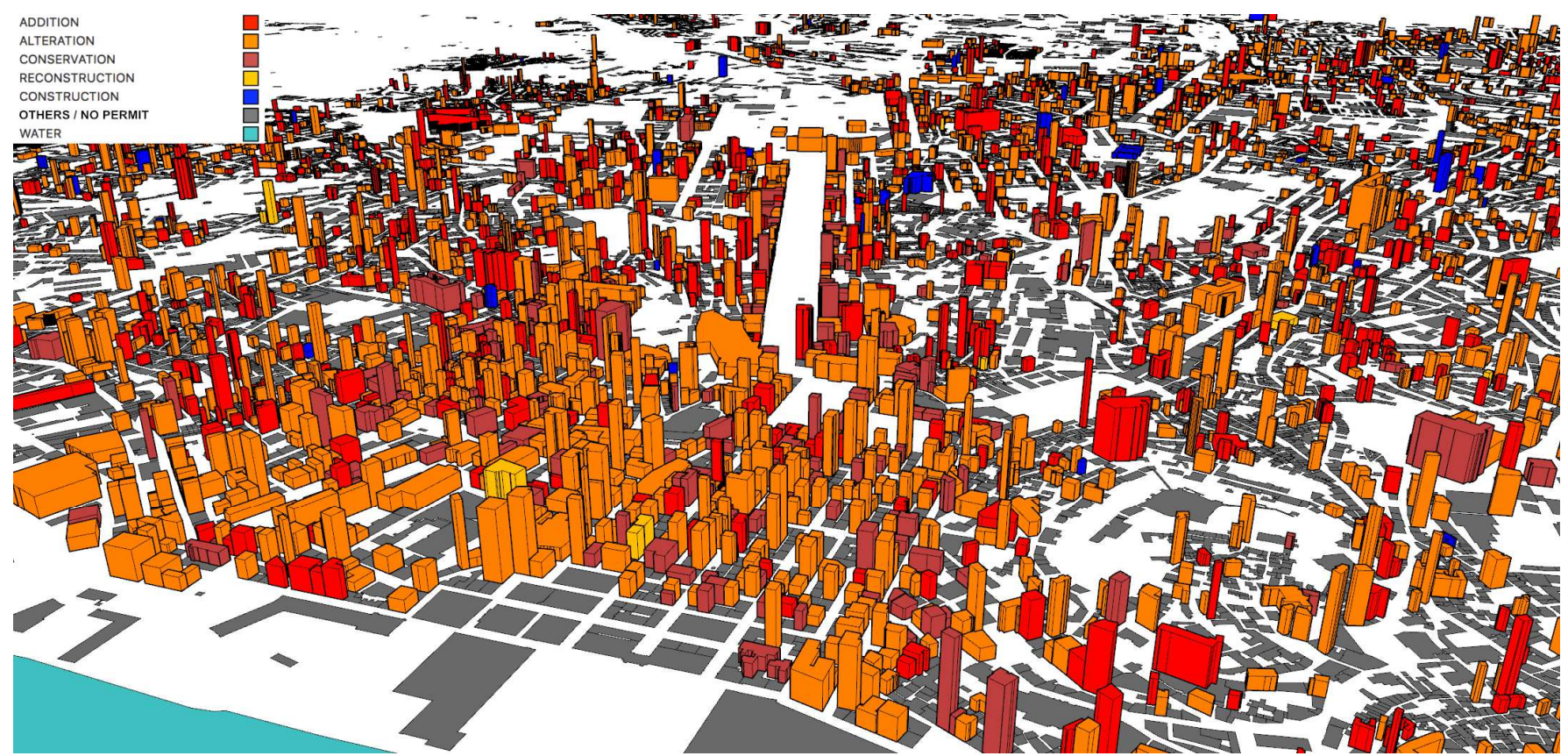

Figure 1: Map of distribution and length of permit approval process in the center of Lisbon (no scale) 
An Alteration is a change to the existing building maintaining its volume, but not either its structure, stairs, facades or infrastructure. All other types of interior refurbishment, like changing the dimensions of compartments, aren't required to submit for a building permit. An expansion or addition is a change of the building original volume and/or plan, and a Reconstruction is demolishing the existing structure, maintaining or not the existing façade, and rebuilding it within the same volume and plan. While Conservation works are those required to return the structure's exterior envelope to its original condition. Thus, in Lisbon, the city hall control of Renovation is limited to construction works that may interfere with city planning and management, consequently it doesn't include all the renovation works that may occur at any given time. In any case, it can be considered a proxy for the actual volume of renovation construction work. In Toronto, 20 categories were gathered into the same 3 groups and the Renovation group includes categories Building Additions/Alterations, Small Residential Projects and, to a less extent, infrastructural projects. Some of the Small Residential Projects category include types of permit that don't need licencing in Lisbon.

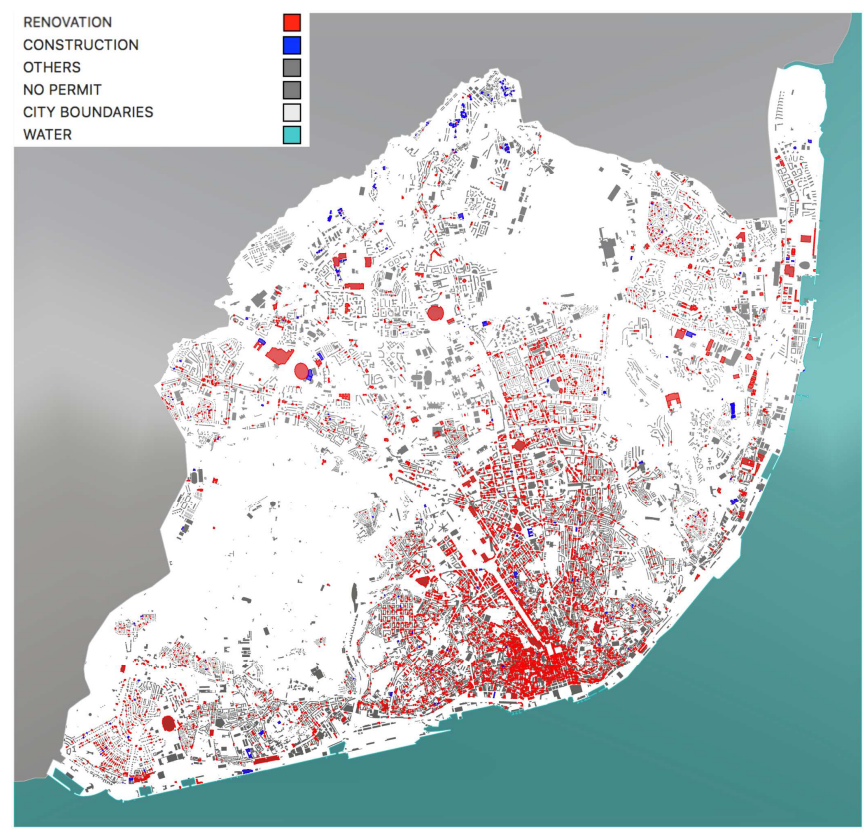

Figure 2: Map of the distribution of Renovation and Construction building permits in the city of Lisbon (no scale)

The Lisbon City Hall cartographic base has a unique GIS ID for each building which relates the shapefile with the building permits database. Although this system has been used since 2003, it was not until 2009 that all the building permit types have systematically used the IDs in the database. Thus, to assure data consistency, only entries from 2010 to 2016 were considered. The Toronto cartographic base also has a unique GIS ID for each building and the permit table can be crossreferenced using the referred ID. The Toronto open data site discloses permit database records since 2000. To ensure the results are comparable across the two cities, only the permits requested and issued in the same period used in Lisbon were included.

\section{Results}

The Lisbon database has three dates registered: application, approval and permit issue; whereas in Toronto only the last and the first dates are registered. The intermediate date in Lisbon is characteristic of the administrative process, it means the application has been accepted but the permit is not issued until the applicant pays the city construction tax and presents further documents. Consequently, the fact that there is an acceptance by the city hall doesn't imply that the construction will take place. Thus, these intermediate dates where ignored.

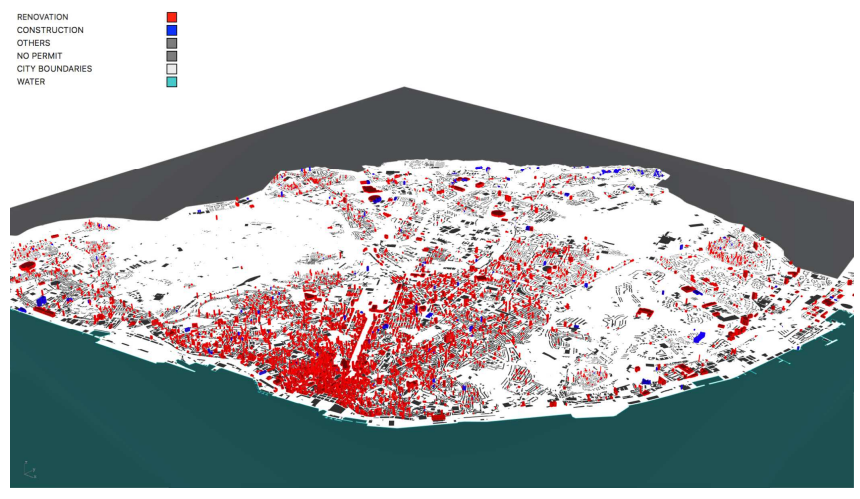

Figure 3: Bird's eye view of the distribution of Renovation and Construction permits on the city of Lisbon

The Lisbon database contains 13964 entries which correspond to 7662 unique entries in the building GIS ID. Duplicate entries can happen in several circumstances: different permit applications for the same building, either in different horizontal properties or for the same property at different times, simultaneous building permit applications for two horizontal properties within the same building polygon. The latter case is responsible for most of the duplicate GIS IDs. Considering the simultaneity of these applications, and for representing time and location of renovation in the city, the duplicate entries can be purged. The Toronto database contains 129734 entries which correspond to 40826 unique entries in the building GIS ID. Duplicate entries corresponded also to different permit applications for the same building or simultaneous building permit applications for two horizontal properties within the same plot or building polygon. The duplicate entries can be purged, and for representing time and location of renovation in both cities, the renovation group entries must prevail.

\section{Three-dimensional approach}

A parametric modelling environment and a shapefile importer plugin were used to import and cross-reference the dates of submission and issuing of building permits and the type of permit with the building polygon on the shapefile, using the GIS ID. The polygons are extruded along the $z$ axis, proportionally to the time past between both dates. Approved building permit applications which have no permit issue date are considered ongoing. For this work $31^{\text {st }}$ December 2016 was used as a cutoff date so that ongoing permits don't get distorted, in an actual application the current date can be used. Types of permit are represented with different colours, whereas the building polygons without permit application are kept grey and flat 


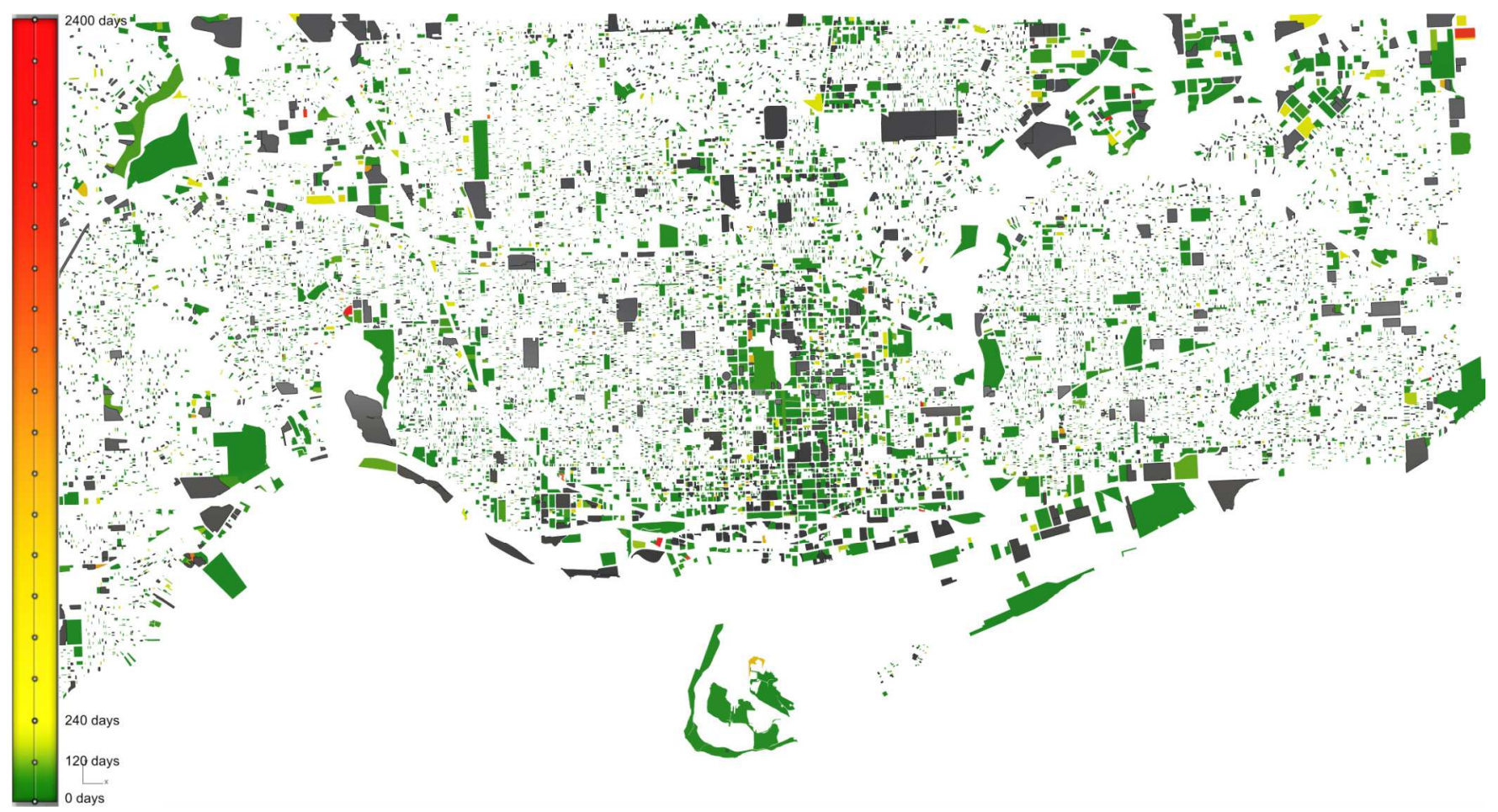

Figure 4: Map of building permit approval time of Renovation and Construction in Toronto (no scale) (Grey - other permit types)

(Figure 1). This type of representation is useful at the neighbourhood scale but not at the city scale, where for the vertical extrusion to be perceivable, occlusion problems start to impair the readability of the map (Figure 3). Thus, at the city scale a bi-dimensional view is needed, rendering the timebased information illegible (Figure 2). Also, at these scales, fewer colours enhance the clarity of the images, hence merging the renovation permit types into one colour allows for a sharper contrast providing insights on possible centralities of renovation. Another possible approach is to use a colour gradient to communicate permit approval length (Figure 4), which precludes distinguishing Renovation and Construction permits.

\section{Video approach}

A GIS software and a plugin that creates image sequences of time varying information were used to animate the permit process duration (Figure 6). A similar method to the previous approach was used to process the entry and withdrawal dates, this information was used to colour the corresponding building polygons. While a planning application is ongoing the polygon is highlighted with the corresponding building permit type colour. The quality of the animation is dependent on how time is compressed into discrete periods which are represented on frames. Several experiences were made of dividing the study timeframe into 1, 2, 4 and 6 months' periods. We found the 2 months' period to be a good compromise between representation precision, in relation to the actual time elapsed in the building permit process, video length and speed. The resulting frames are then exported to MPEG4 video format. As with the three-dimensional approach, the video approach is useful at the neighbourhood scale, at the city scale much of the detail is lost.

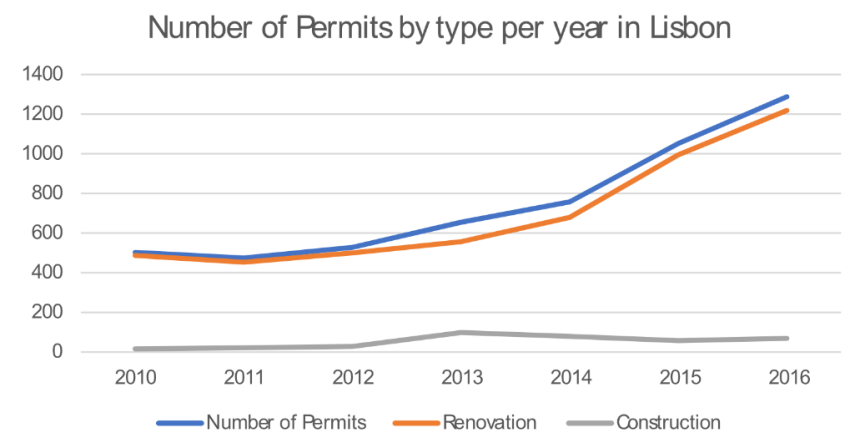

Graph 1: Number of permits by type per year in Lisbon 


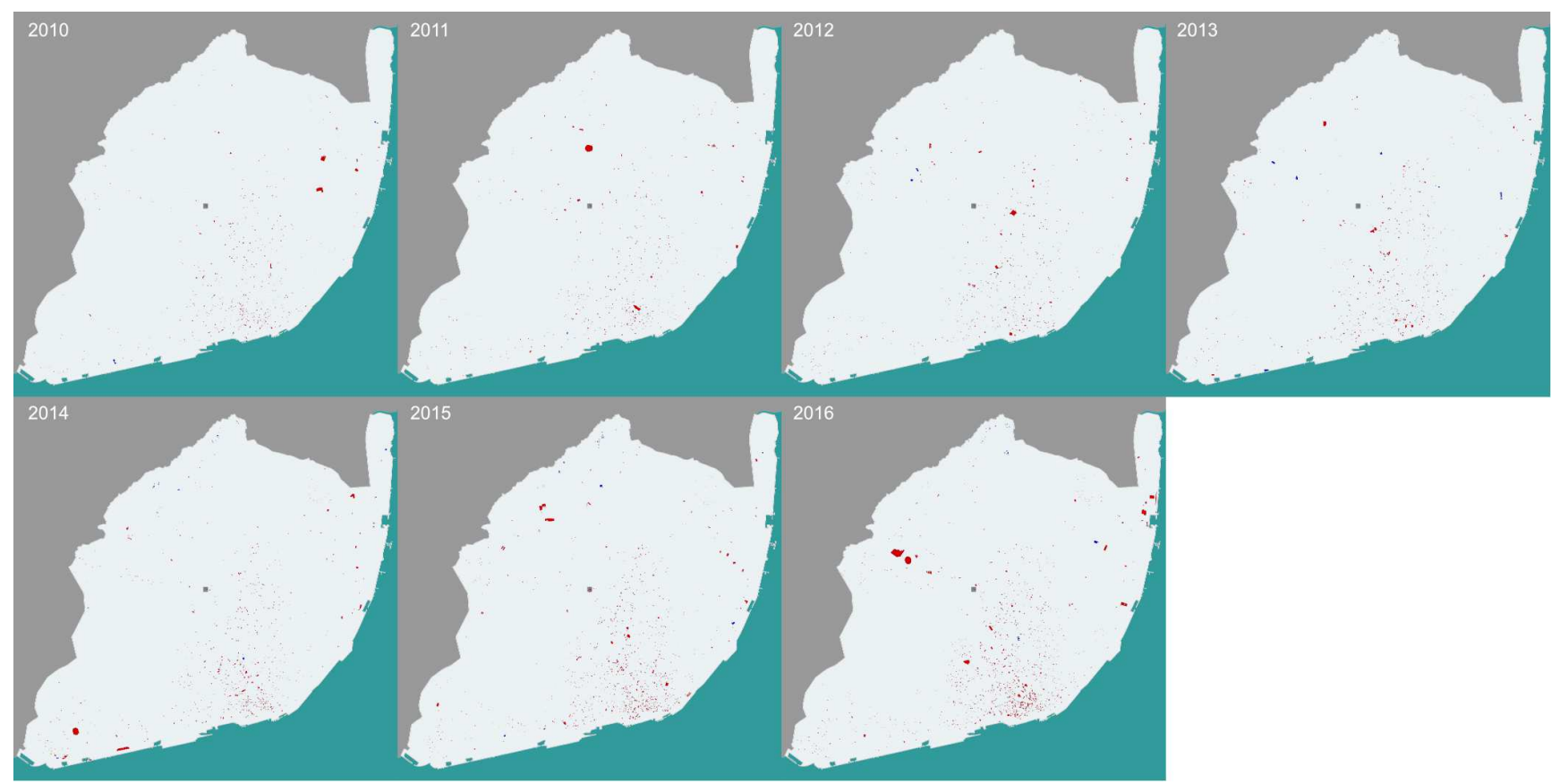

Figure 5: Yearly Maps of renovation and construction permits

\section{City Renewal Trends}

Renovation permits in Lisbon in the period 2010 to 2016 are heavily weighted towards the old city downtown and its XIX century expansions, which confirms casual observations of city dwellers of an urban renewal focused in these areas. Whereas in Toronto there is a greater dispersion of permits throughout the city, even if the downtown area still shows higher concentrations of permits than the rest of the city. Another important trend detected in Lisbon was the increase in renovation permits throughout the observed period, nearly tripling from 487 in 2010 to 1219 in 2016 and with steady increases year-on-year from 2012 to 2016 (Graph 1). Construction permits show a less clear trend, increasing from 16 permits in 2010 to 69 in 2016, with a peak of 98 in 2013. Toronto presents similar trends both in renovation and construction, with 1343 in 2010 growing to 3778 in 2016. Spatially, as can be observed from the yearly images of Lisbon (Figure 5), there is a clear increase of permits from 2010 to 2016 concentrated in the downtown -Baixa area spreading towards Lisbon's largest avenue -Avenida da Liberdade area, while in other areas no specific trend is visible.

\section{Visualization improvement techniques}

Both in Lisbon and Toronto, the method revealed limitations when dealing with horizontal property of buildings, since each
GIS ID is related with a building polygon and not to a full address ID, all horizontal properties within a building share the same GIS ID. Subsequently in both cities, if different proprietors within the same building apply for building permits these applications will be classified with the same GIS ID. Even if data analysis revealed that in the case of Lisbon, most duplicate entries are simultaneous applications, in Toronto it was less so. Besides to further analyse the rate of the city renewal it is important to understand whether it is the entire building that is being renovated or only a specific part. Currently neither city has horizontal property integrated across its open data GIS ID system, but Toronto already has open data 3D shapefiles, and Lisbon has a small part of the city with full address GIS ID. Future work should focus on devising visualization methods that are able to cope with multiple properties on a single polygon or 3D shape.

The current approach revealed accurate to illustrate the urban renovation phenomena in cases that a building has a single permit issued. When a building has several permits the proposed visualizations require some enhancement regarding the mapping of subdivisions. 

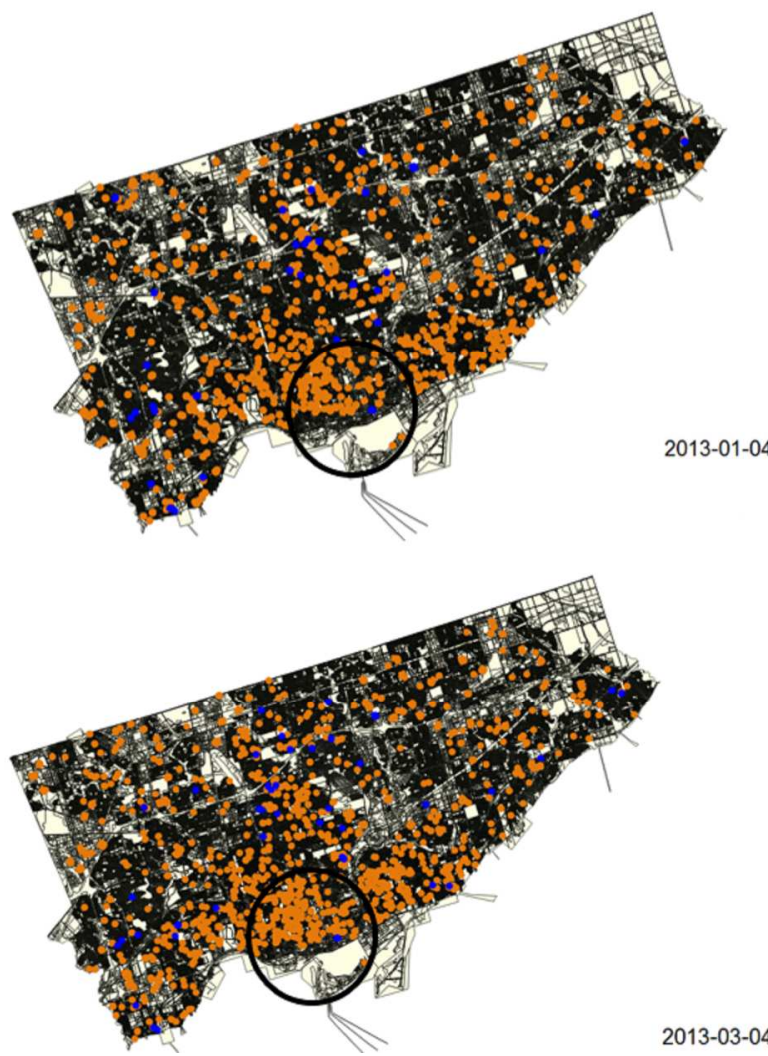
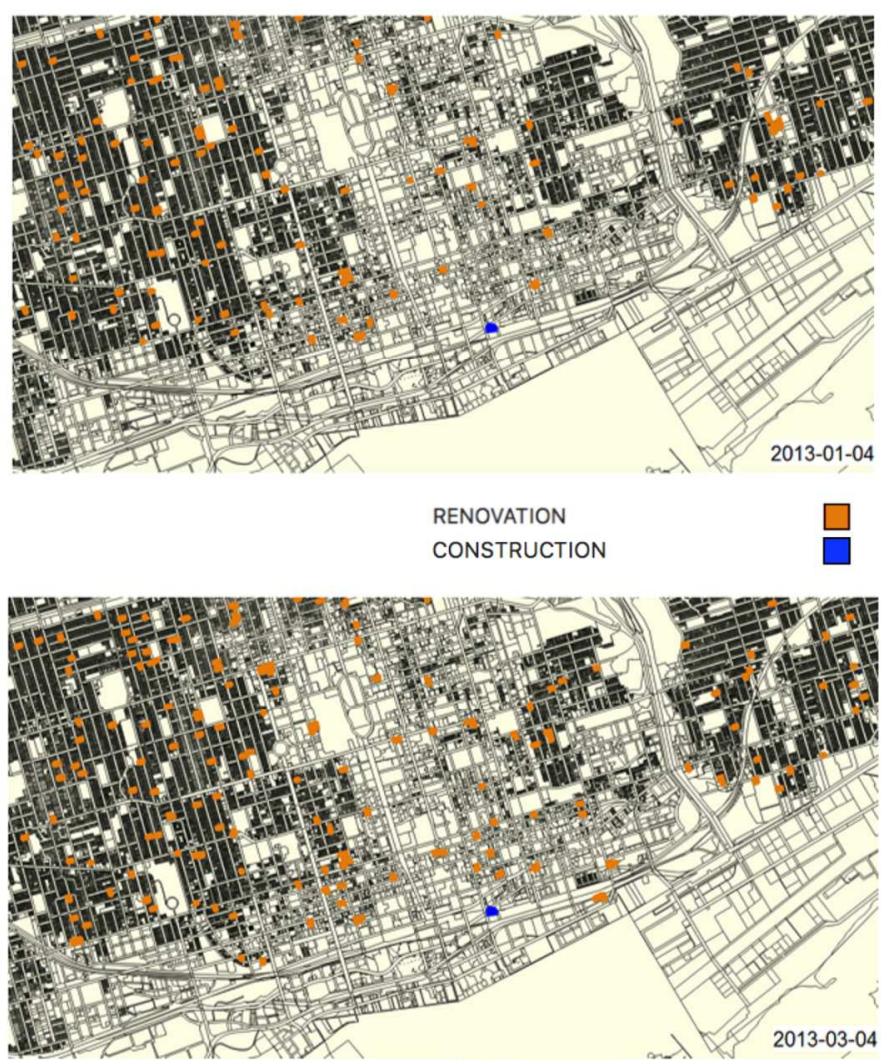

Figure 6: Video photograms of 2-month evolution in City of Toronto municipal wards and in City Center

\section{Discussion}

This work made use of data and tools that are pervasive in most city halls. Many City Halls, such as Toronto, already provide open access to this data to the public, normally in spreadsheet or database formats. These are comprehensive and powerful ways of sharing data, but require some time and knowledge to be processed into accessible information. Maps on the other hand are a far more accessible way of presenting urban data. This paper presents a method by which this data can be transformed into maps that can be made available in real-time to the public, both while the building permitting process occurs or even during construction phase. Two alternative ways of representing time on a map were explored. Using parametric modelling, time was represented on the vertical axis while using GIS time was compressed and represented in a video.

These representations can portray time and space dynamics of urban renewal on the territory where they occur, overcoming the lack of spatial information and local detail in traditional statistical representations. This can be useful for planning purposes, showing local specificities, local concentration or dispersion of renovation, which would otherwise be lost in more synthetic forms of representation. It could also be a useful to tool to improve public participation and information of ongoing changes in the city. For architects, it could be useful for having access to insight over future changes in an area where they are also developing projects in while also providing information on average length of building permit approval.

While these maps are useful at a neighbourhood level, at the city scale they become harder to visualise. We foresee that using statistical methods, such as Kernel Density Estimation or Getis-Ord Gi, with these datasets could provide a better balance between analytic and synthetic representations, without the loss of the underlying spatial information. Another advantage of these methods is the capacity to provide readability at the city scale.

This paper is part of an ongoing research that aims to characterize the urban renewal process and building renovation trend currently evolving in Portugal, developing new tools that contribute to extend the boundaries of urban data visualization, analysis and synthesis. The analysis of these maps revealed that there is an important focus of renovation going on within the historic city centre, extending to its XIX century expansion, and to a lesser extent to other more recent areas built during the $\mathrm{XX}$ th century.

In the context of Lisbon, the length of the administrative process, that a visualization such as this makes evident, provides an important reason why designers should rethink the process of designing for building renovation, and city halls should revise and speed up the review of building permit applications. Unlike in a new building, a renovation project acts upon a structure that exists and is degrading. If designers follow the traditional sequence of concept design, building permit application, detail design and only later procure a 
contractor, many options of renovation are going to be curtailed eventually leading to a less sustainable building renovation process. There seems to be a clear benefit of a more interdisciplinary process of design, where all actors collaborate from the onset of the project, not only shortening the process but more importantly broadening the set of solutions available at the start.

\section{Acknowledgments}

We would like to thank the support of Lisbon City Hall. This work was developed with the support of an ISTA merit scholarship grant and is part of an ongoing $\mathrm{PhD}$ research.

\section{References}

Alexander, C. (1966) 'A city is not a tree', Design. London, 206, pp. 117. Available http://www.chrisgagern.de/Media/A_City_is_not_a_tree.pdf.

Batty, M. (2006) 'Hierarchy in cities and city systems', in Hierarchy in natural and social sciences. Springer, pp. 143-168.

Batty, M. (2012) 'Research, Write, Type, Submit, Pass, and 30 Years Later $\{\ldots\} . . \quad$ Smart Cities'. Available at: http://www.spatialcomplexity.info/archives/747 (Accessed: 24 January 2017).

Batty, M. (2015) 'Data About Cities: Redefining Big, Recasting Small', CASA Working Papers Series, (203), pp. 0-18. doi: 10.1103/PhysRevE.78.016110.
Batty, M. (2016) 'Classifying urban models', Environment and Planning B: Planning and Design, 43(2), pp. 251-256. doi: $10.1177 / 0265813516630803$.

Batty, M., Besussi, E. and Chin, N. (2003) 'Traffic, Urban Growth and Suburban Sprawl', pp. 18-19. Available at: www.casa.ucl.ac.uk.

Batty, M. and Longley, P. A. (1994) 'Fractal cities: a geometry of form and function'. Academic press.

Batty, M. and Xie, Y. (1994) 'From cells to cities', Environment and Planning B: Planning and Design, 21, pp. 31-48.

Bruton, D. (1997) A contingent sense of grammar. University of Adelaide.

Claudel, M., Nagel, T. and Ratti, C. (2015) 'From Origins to Destinations: The Past, Present and Future of Visualizing Flow Maps', Built Environment. Alexandrine Press, 42(3), p. 200. Available at: http://www.alexandrinepress.co.uk/Announcing-BigData-Issue.

INE (2016) Estatísticas da Construção e Habitação 2015. Lisboa.

Offenhuber, D., Wolf, M. and Ratti, C. (2013) 'Trash track - active location sensing for evaluating e-waste transportation'.

Ratti, C. (2006) 'Real Time Rome'. Available at: http://senseable.mit.edu/realtimerome/ (Accessed: 25 January 2017).

Robinson, A. H. (1967) 'The thematic maps of Charles Joseph Minard', Imago Mundi, 21(1), pp. 95-108. doi: $10.1080 / 03085696708592302$.

Steadman, P. (1979) The Evolution of Designs: Biological Analogy in Architecture and the Applied Arts. Taylor \& Francis. 